\title{
ANATOMÍA PATOLÓGICA DE LA PATOLOGÍA DE TIROIDES Y PARATIROIDES. SISTEMA BETHESDA DEL DIAGNÓSTICO CITOLÓGICO DE LA PATOLOGÍA DE TIROIDES
}

\section{Thyroid and Parathyroid Gland Pathology. The Bethesda System for Reporting Thyroid Cytopathology}

Jesús PINTO-BLÁZQUEZ; Inmaculada URSÚA-SARMIENTO

Complejo Asistencial de Zamora. Servicio de Anatomía Patológica. Zamora. España

Correspondencia:jpintob@saludcastillayleon.es

Fecha de recepción: 15 de octubre de 2019

Fecha de aceptación: 17 de octubre de 2019

Fecha de publicación: 19 de octubre de 2019

Fecha de publicación del fascículo: 1 de septiembre de 2020

Conflicto de intereses: Los autores declaran no tener conflictos de intereses

Imágenes: Los autores declaran haber obtenido las imágenes con el permiso de los pacientes

Política de derechos y autoarchivo: se permite el autoarchivo de la versión post-print (SHERPA/RoMEO)

Licencia CC BY-NC-ND. Licencia Creative Commons Atribución-NoComercial-SinDerivar 4.0 Internacional

Universidad de Salamanca. Su comercialización está sujeta al permiso del editor

RESUMEN: Introducción y objetivo: La PAAF es el mejor método para el manejo de pacientes con nódulos tiroideos, como método de cribado y para seleccionar a los pacientes que pueden ser sometidos a tratamiento quirúrgico. El objetivo de este artículo es hacer una breve descripción de las categorías diagnósticas del Sistema Bethesda en su segunda edición (2018). Síntesis: El Sistema Bethesda establece 6 categorías diagnósticas: Insatisfactorio /No diagnóstico, Benigno, Atipia de significado Indeterminado/ Lesión folicular de significado indeterminado, Neoplasia folicular/Sospechoso de neoplasia folicular, Sospechoso de Malignidad Maligno. Cada categoría lleva implícito el riesgo de malignidad y el manejo de estos pacientes, con lo cual el diagnóstico va a influir en la actitud a seguir. Conclusiones: El Sistema Bethesda permite a los patólogos realizar informes sistematizados y al clínico establecer la actitud a seguir en función de cada categoría diagnóstica.

PALABRAS CLAVE: Tiroides; Bethesda; PAAF. 


\section{ANATOMÍA PATOLÓGICA DE LA PATOLOGÍA DE TIROIDES Y PARATIROIDES. SISTEMA BETHESDA DEL DIAGNÓSTICO CITOLÓGICO DE LA PATOLOGÍA DE TIROIDES PINTO-BLÁZQUEZ J; URSÚA-SARMIENTO I}

SUMMARY: Introduction and objective: The FNA is the best method for the management of patients with thyroid nodules, as a screening method and for selecting patients who can undergo surgical treatment. The objective of this article is to make a brief description of the diagnostic categories of the Bethesda System in its second edition (2018). Synthesis: The Bethesda System establishes 6 diagnostic categories: No diagnostic-Unsatisfactory, Benign, Atypia od Undetermined Significance/Follicular Lesion of Undetermined Significance, Follicular Neoplasm/Suspicious for a Follicular Neoplasm, Suspicious for Malignant and Malignant. Conclusions: The Bethesda System allows pathologists to make systematized reports and the clinician to establish the attitude to follow according to each diagnostic category.

KEYWORDS: Thyroid; Bethesda; PAAF.

\section{INTRODUCCIÓN}

La prevalencia e incidencia de nódulo tiroideo en nuestro medio es alta. La incidencia oscila entre un $4 \%$ a $6 \%$ con exploración física, y aumenta hasta un $20 \%$ a $40 \%$ con ecografía. Dicha incidencia aumenta con la edad [1-2].

Durante los últimos años la PAAF ha demostrado ser método más útil para el estudio de un nódulo tiroideo, no solo como método de cribado (se ha disminuido el número de intervenciones quirúrgicas en lesiones benignas que son seguidas por PAAF) sino también para seleccionar los pacientes candidatos a tratamiento quirúrgico. Además es una técnica, no invasiva, de bajo coste y con escasas complicaciones que en ningún caso comprometen la vida del paciente [3].

A lo largo de la historia los informes de PAAF eran descriptivos, no sistematizados, no comparables y rara vez indicaban el manejo del paciente. Esto ha cambiado radicalmente después de la Reunión Multidisciplinar de expertos en patología tiroidea celebrada en Bethesda 2007, se realiza el manual de la Nomenclatura y Sistemática de elaboración de los informes de PAAF tiroidea, de la que se ha publicado una segunda edición en 2018. Dicha clasificación establece 6 categorías diagnósticas e indica en cada categoría el riesgo de malignidad y el manejo clínico-terapéutico del paciente [4-6].

El objetivo de este artículo es hacer una revisión de cada categoría diagnóstica del Sistema
Bethesda 2018, estableciendo una correlación clínico-patológica, de algunas entidades [4].

\section{CATEGORÍAS DIAGNÓSTICAS DE LA \\ CLASIFICACIÓN DE BETHESDA 2018. CORRELACIÓN CITOHISTOLÓGICA}

Categoría 1: No diagnóstica/ insatisfactoria.

Una PAAF de tiroides se considera adecuada cuando hay al menos 6 grupos con al menos 10 células foliculares bien visualizadas y preservadas (preferiblemente en una preparación en las suele haber material coloide y las células forman grupos o macrofolículos de células homogéneas equidistantes sin atipia), salvo en tres excepciones:

- Nódulo sólido en el que hay atipia citológica en la PAAF. Nunca debe considerarse insatisfactorio.

- Nódulo sólido con inflamación. Debe considerarse benigno y no requiere 6 grupos con al menos 10 células foliculares.

- Extendidos con abundante material coloide. Deben considerarse benignos aunque no haya al menos 6 grupos con 10 células foliculares.

Deben considerarse insatisfactorias las PAAF con menos de 6 grupos con al menos 10 células foliculares (salvo en las 3 excepciones anteriormente descritas), las PAAF con mala calidad de la muestra (intenso artefacto) o las que muestran material hemático, musculo o células cilíndricas de tipo respiratorio, sin células foliculares. Incluye en 


\section{ANATOMÍA PATOLÓGICA DE LA PATOLOGÍA DE TIROIDES Y PARATIROIDES. SISTEMA BETHESDA DEL DIAGNÓSTICO CITOLÓGICO DE LA PATOLOGÍA DE TIROIDES PINTO-BLÁZQUEZ J; URSÚA-SARMIENTO I}

este grupo las punciones en el que hay contenido quístico con menos de seis grupos con 10 células foliculares.

El riesgo de malignidad en esta categoría está entre $5-10 \%$ y en el manejo se recomienda repetir la PAAF guiada por ecografía.

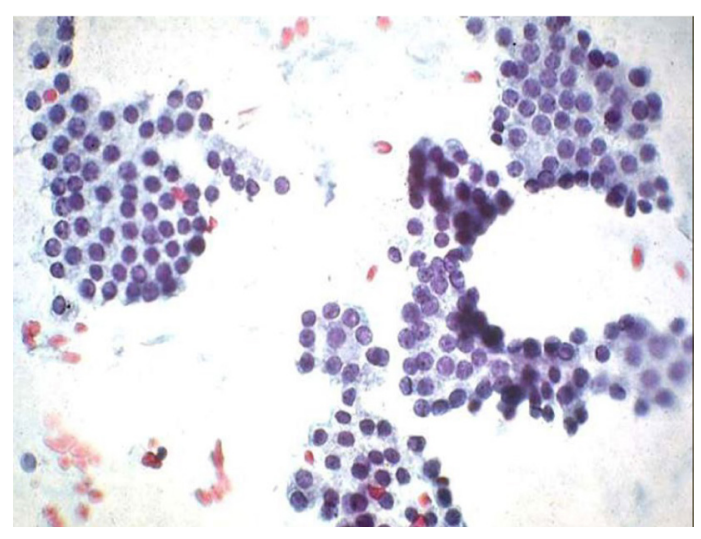

Figura 1. PAAF de nódulo folicular benigno que muestra extendidos con macrofolículos células foliculares típicas en monocapa (Tinción con Giemsa. Magnificación original x100).

\section{Categoría 2: Benigna.}

Es la más frecuente (60-70\%). Se incluyen dentro de esta categoría:

- Nódulo folicular benigno, en el que se incluyen la hiperplasia nodular, nódulo adenomatoide, nódulo coloide y nódulo en pacientes con enfermedad de Graves.

- Tiroiditis linfocítica.

- Tiroiditis granulomatosa.

- Tiroiditis aguda.

- Tiroiditis de Riedel.

La entidad más frecuente es el nódulo folicular benigno, cuya PAAF se caracteriza por extendidos con abundante coloide, grupos de células foliculares típicas en monocapa y celularidad histiocitaria.

Las piezas de tiroidectomía con bocio multinodular muestran una glándula multinodular con nódulos de tamaño variable en algunos de los cuales suele haber degeneración quística y hemorragia.
Histológicamente presentan folículos tiroideos grandes distendidos, con coloide, revestidos por células epiteliales en monocapa cuboideas o cilíndricas. Suele haber áreas de hemorragia, calcificación distrófica, fibrosis, con macrófagos con pigmento hemosiderínico y degeneración quística con cristales de colesterol.

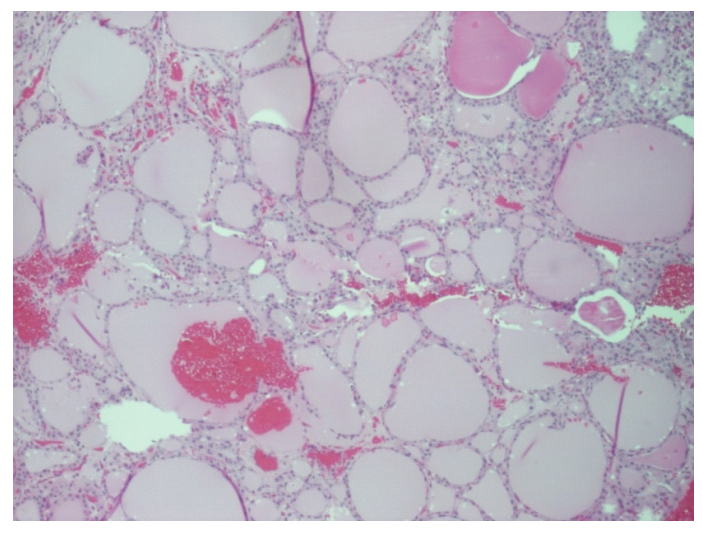

Figura 2. Imagen histológica de bocio multinodular: Folículos grandes distendidos, revestidos por células epiteliales cuboideas en monocapa (Tinción con hematoxilina, magnificación original x40).

Otro diagnóstico dentro de la categoría de benignidad incluye las tiroiditis. La PAAF de la tiroiditis granulomatosa se caracteriza por la presencia de células gigantes multinucleadas, células epitelioides y células foliculares con o sin metaplasma oncocítica, entre las que se observa un infiltrado inflamatorio mixto. Histológicamente muestra un agrandamiento asimétrico vagamente nodular, de consistencia firme con celularidad inflamatoria que afecta a la glándula de forma desigual, alternando áreas con inflamación activa con leucocitos polimorfonucleares, linfocitos, células plasmáticas y células gigantes multinucleadas y áreas donde el proceso inflamatorio se va resolviendo, en las que predomina la fibrosis cicatricial [7].

La tiroiditis linfocítica fue descrita se caracteriza citológicamente por una mezcla de células 


\section{ANATOMÍA PATOLÓGICA DE LA PATOLOGÍA DE TIROIDES Y PARATIROIDES. SISTEMA BETHESDA DEL DIAGNÓSTICO CITOLÓGICO DE LA PATOLOGÍA DE TIROIDES PINTO-BLÁZQUEZ J; URSÚA-SARMIENTO I}

linfoides y oncocíticas (células de Hürthle). El infiltrado linfoide es denso, polimorfo, con linfocitos, células plasmáticas y células de centro germinal. Las piezas quirúrgicas con tiroiditis linfocítica muestran un agrandamiento simétrico, de consistencia firme y color pálido y muestra un marcado infiltrado linfocitario con centros germinales y células oncocíticas con amplio citoplasma eosinófilo, y núcleos grandes con nucleolo prominente [8].

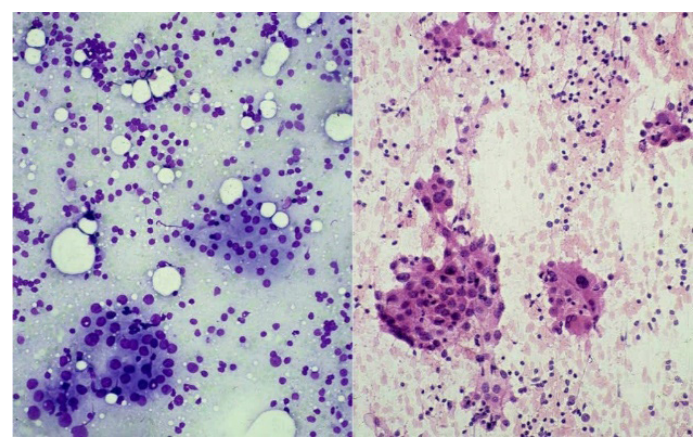

Figura 3. PAAF benigna (categoría 2) de tiroiditis de linfocítica que muestra extendidos con mezcla de células linfoides polimorfas y células epiteliales oncocícitas (Tinción con Giemsa y Papanicolau, magnificación original x 40).

CATEgoría 3: Atipia de significado indeterminado / Lesión folicular de significado indeterminado.

En esta categoría se incluyen las PAFF en las que hay atipia citológica, arquitectural o ambas, pero no suficiente para clasificarla como sospechosa o neoplasia folicular. La atipia citológica puede ser de células linfoides o epiteliales. Se incluye en esta categoría la presencia de células «histiocitoides», punciones con células oncocíticas en escasa cuantía y atipia no especificada (NOS) en la que se observan núcleos grandes con nucleolo prominente en pacientes que han sido tratados con iodo radiactivo, carbimazol u otros agentes farmacológicos y punciones en las que se observan cuerpos de psamoma pero no se observan núcleos con hallazgos de carcinoma papilar. El Sistema Bethesda recomienda repetir la PAFF en estos pacientes.

Categoría 4: Neoplasia folicular / sospechosa de neoplasia folicular.

Se incluye en esta categoría PAAF con moderada-alta celularidad constituida por células que forman microfolículos y escaso o nulo coloide. Las células foliculares tienen núcleos uniformes con escaso citoplasma. Incluye en esta categoría la neoplasia de células oncocíticas en las que la celularidad está constituida por células oncocíticas. El Sistema Bethesda recomienda en estos pacientes realizar lobectomía o técnicas moleculares ya que la PAAF no distingue entre un adenoma y un carcinoma folicular, siendo el diagnóstico histológico (en el carcinoma folicular hay invasión vascular o capsular y en el adenoma no). Los mismos criterios se incluyen para los tumores de células de Hürhle [9].

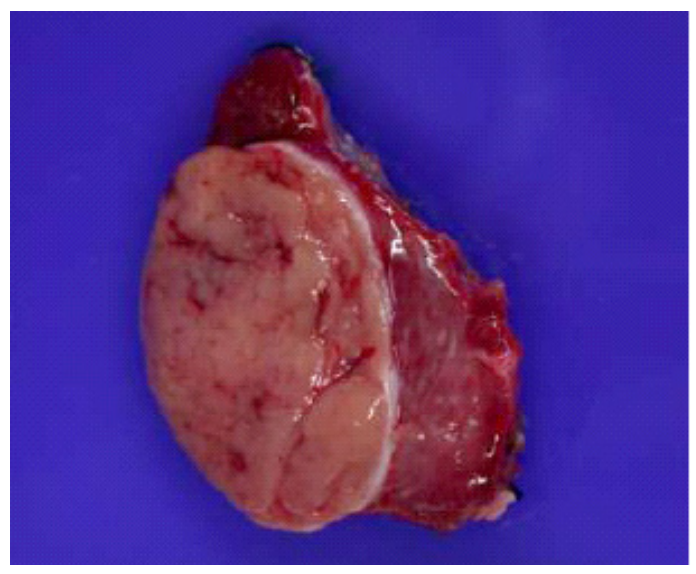

Figura 4. Fotografía macroscópica de adenoma folicular: tumor encapsulado revestido por una cápsula gruesa de superficie parduzca, carnosa al corte.

\section{Categoría 5: Sospechosa de malignidad.}

Incluye lesiones con datos citológicos altamente sospechosos de malignidad pero no suficientes para concluir un diagnóstico. Incluye lesiones 


\section{ANATOMÍA PATOLÓGICA DE LA PATOLOGÍA DE TIROIDES Y PARATIROIDES. SISTEMA BETHESDA DEL DIAGNÓSTICO CITOLÓGICO DE LA PATOLOGÍA DE TIROIDES PINTO-BLÁZQUEZ J; URSÚA-SARMIENTO I}

sospechosas de carcinoma papilar, sospechosas de carcinoma medular, sospechosas de linfoma y sospechosas de malignidad, no especificada. El Sistema Bethesda recomienda en estos pacientes cirugía (lobectomía o tiroidectomía).

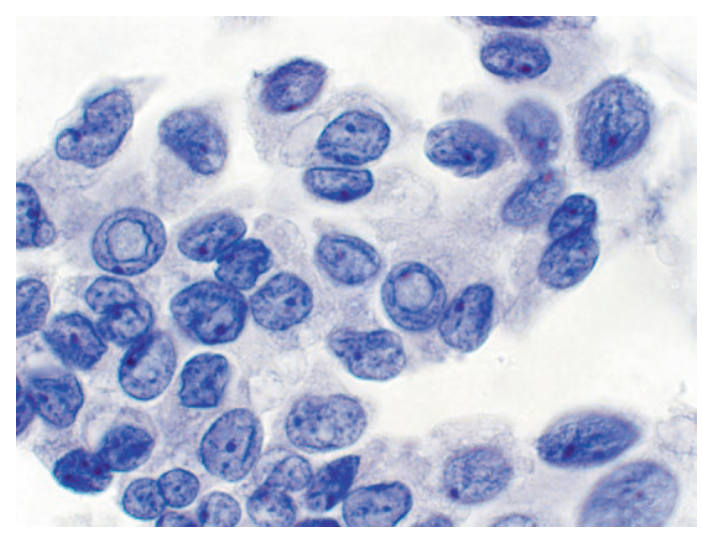

Figura 5. Carcinoma papilar, con células con núcleos pálidos, vacíos en vidrio esmerilado con hendiduras y pseudoinclusiones nucleares (Tinción con Giemsa, x 200).

\section{Categoría 6: Maligno.}

Incluye casos con características citológicas concluyentes de malignidad dentro de las que se incluye carcinoma papilar y sus variantes, carcinoma medular y variantes, carcinoma pobremente diferenciado, carcinoma indiferenciado (anaplásico), linfoma y metástasis.

El tumor maligno más frecuente es el carcinoma papilar 85\%. Los hallazgos citológicos diagnósticos son diagnósticos son nucleares. Las células forman papilas o estructuras en monocapa. Muestran células con núcleos grandes, con superposición nuclear con aclaramiento de la cromatina y acentuación de la membrana nuclear, dando aspecto en vidrio esmerilado, con núcleos vacíos, pálidos, con hendiduras o pseudoinclusiones nucleares. Dentro de las variantes se incluye la neoplasia tiroidea folicular no invasiva con hallazgos nucleares papilarlike que sustituye al carcinoma papilar variante folicular encapsulado. Histológicamente pueden mostrar diversos patrones dentro del mismo tumor, papilar, sólido, trabecular, folicular o quístico, con papilas complejas, arborizadas, ramificadas y estrechas, con coloide denso hipereosinófilo, y células que muestran núcleos con características descritas anteriormente. Se observan cuerpos de psamoma hasta en el 50\% de los casos [10].

El carcinoma medular suele ser un tumor unilateral y solitario en casos esporádicos y multifocal o bilateral en casos familiares. Las PAAF se caracterizan por moderada-alta celularidad con células poligonales, plasmocitoides o fusocelulares con núcleos con cromatina en sal y pimienta. Es característico el depósito de amiloide. Hay diversas variantes de carcinoma medular. Se observa amiloide en el estroma en el 70-80\% de los casos. Es necesario realizar calcitonina por inmunohistoquímica para confirmar el diagnóstico [4].

El carcinoma anaplásico es un tumor muy agresivo de rápido crecimiento y mal pronóstico. Se caracteriza por una abundante celularidad, pleomórfica con células epitelioides o fusiformes. Muestra núcleos grandes pleomórficos, irregulares con macronucleolos, mitosis y necrosis. En el estudio de piezas quirúrgicas se caracteriza por grandes masas tumorales que reemplazan en ocasiones la mayor parte del tejido tiroideo con extensión extratiroidea [4].

Los linfomas primarios tiroideos son más frecuentes en mujeres mayores con historia de tiroiditis de Hashimoto. Los más frecuentes son el linfoma difuso de célula grande B y el linfoma $B$ de la zona marginal extraganglionar (MALT) para cuyos diagnósticos se requiere restricción de cadenas ligeras y marcadores inmunohistoquímicos ya que la PAAF del linfoma MALT es muy similar a la de un ganglio reactivo [4].

Cuando estudiamos una PAAF con signos citológicos de malignidad debemos tener en cuenta que puede tratarse de una metástasis tiroidea. Los tumores que más frecuentemente metastatizan en tiroides son los originados en pulmón, mama, piel (especialmente el melanoma), colon y riñón. Las metástasis pueden presentarse como múltiples nódulos de menos de $2 \mathrm{~mm}$, nódulo único grande 


\section{ANATOMÍA PATOLÓGICA DE LA PATOLOGÍA DE TIROIDES Y PARATIROIDES. SISTEMA BETHESDA DEL DIAGNÓSTICO CITOLÓGICO DE LA PATOLOGÍA DE TIROIDES PINTO-BLÁZQUEZ J; URSÚA-SARMIENTO I}

y afectar al tiroides de forma difusa. Es necesario la mayoría de las veces realizar técnicas complementarias de inmunohistoquímica para realizar el diagnóstico y conocer los antecedentes del paciente.

\section{CONCLUSIONES}

La clasificación del Sistema Bethesda para el estudio de lesiones tiroideas permite a los patólogos realizar informes sistematizados, unificados, homogéneos, establecer la actitud terapéutica del paciente y seleccionar los pacientes que van a ser candidatos a tratamiento quirúrgico.

\section{BIBLIOGRAFÍA}

1. Henrichens TL. Reading ultrasonography part 2: nodules. Radiol Clin N Am 2011; 49:417-24.

2. Kim MJ, Kim EK, Park SI, Kim BM, Kwak JY, Kim SJ, et al. US-guided fine-needle aspiration of thyroid nodules: indications, techniques, results. Radiographics. 2008; 28:1869-86.

3. Ananthakrishman N, Rao KM,Narasimhan R, Veliath AJ. Problems and limitations with fine- needle aspiration cytology of solitary thyroid nodules. Aust NZ J Surg. 1990; 60(1):35-9.

4. Syed ZA, Cibas ES. The Bethesda System for Reporting Thyroid Cytopatology. Definitions, Criteria and Explanatory Notes. New York: Springer; 2010.

5. Cibas Es, Ali SZ. The Bethesda System for Reporting Thyroid Cytopathology. Am J Clin Pathol 2009; 132:658-65.

6. Syed Z. Ali. Thyroid Cytopathology: Bethesda and Beyond. Acta Cytol. 2011; 55:4-12.

7. Woolner L,McConahey W.Beahrs O. Granulomatous Thiroiditis (de Quervain's thyroiditis). J Clin Endocrinol Metab. 1957; 17:1202-21.

8. Lindasy S, Dailey M. Friedlander J et al. Cronic thyroiditis a clinical and pathological study of 354 patients. J Clin Endocrinol Metab. 1952; 12:15781600.

9. Baloch ZW, Fleisher S, LiVolsi VA, Gupta PK. Diagnosis of «follicular neoplasm»: a gray zone in thyroid fine-needle aspiration cytology. Diagn Cytopathol. 2002; 26(1):41-4.

10. Carcangiu ML, Zampi G, Rosai J. Papillary thyroid carcinoma: a study of its many morphologic expressions and clinical correlates. Pathol Annu. 1985; 20(Pt 1):1-44. 